\title{
Marine embankment slide and reinforcement simulation based on discrete numerical method
}

\author{
Hai-feng XIU1.*, Zhuo-qi SUN², Zun-bang XI', Guo LI ${ }^{2}$ \\ 1. Rural water conservancy management station, Daishan County Water Conservancy Bureau, Daishan 316200, China \\ 2. School of Marine Engineering Equipment, Zhengjiang Ocean University, Zhoushan 316002, China
}

\begin{abstract}
Hybird discrete numerical methods inclusive of DEM and XFEM were developed in the study to simulate the marine embankment slide in Zhejiang coast. The study derived the comprehensive fields that included the displacement, stress, internal forces and reliality factor. Therefore, the typical marine embankment slide simulation and reinforcement effect evaluation were completed. The methods and results were helpful for the marine embankment cases.
\end{abstract}

\section{Introduction}

Zhejiang in China and the neighboring structures were destroyed heavily (Fig.1).

A catastrophic slide went in the marine embankment of

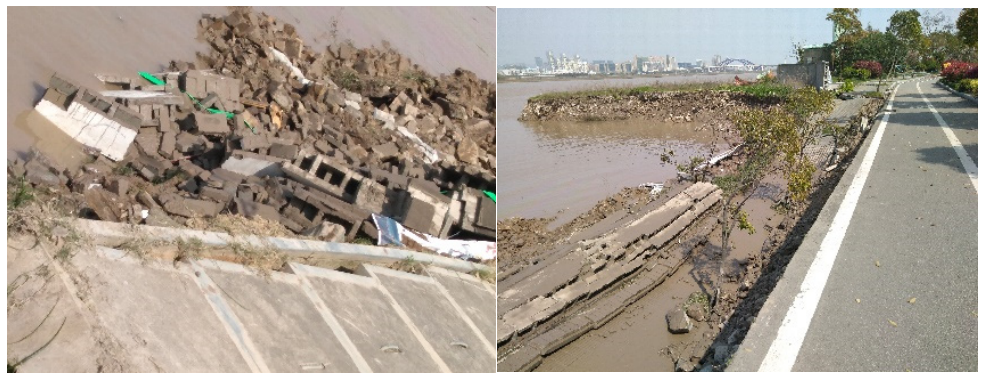

Fig.1 Collapsed marine embankment in-situ

The study adopted the discrete numerical method to simulate the birth of the disaster and the reinforcement technology ${ }^{[1,2]}$.

\section{Discrete numerical method}

Discrete element method (DEM) has been the most popular technique for the geo-materials physical behavior simulation.

DEM pays attention on the calculation on the intersecting forces, velocities and accelerations of the material particles as well as the interfaces. Here Newton's second law has been invited in the computation on the elements' velocities and accelations with the physical hypotheses on the connections between the discrete particles. Therefore, the goal physical fields on the structures can be ascertained during the diverse simulations on the non-linear behaviors ${ }^{[3]}$.

The internal law on the force and displacement of the interface can be expressed that the components of the interactive forces and the relative deformations in tangent and normal directions will be computed with the determination of tangent and normal rigidities. The model can be interpreted by the double-ball and wall-ball connection in Fig. 2. Particularly, the normal unit vector $n_{i}$ from double-ball model can be defined by Eq. (1).

$$
n_{i}=\frac{x_{i}^{[\mathrm{B}]}-x_{i}^{[\mathrm{A}]}}{d}
$$
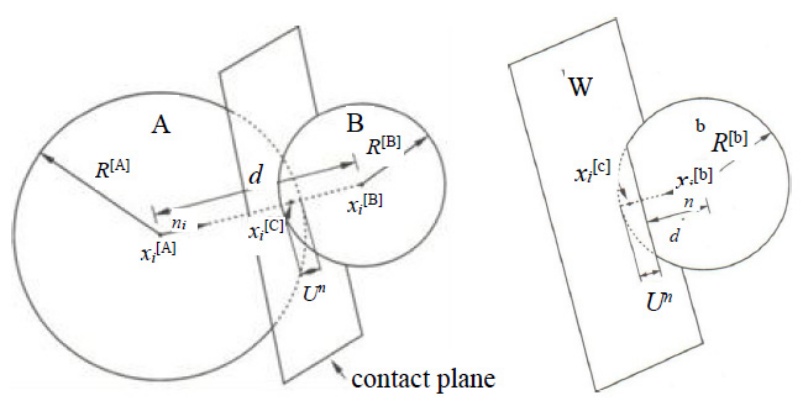

Fig.2 Interfacial model of DEM

\footnotetext{
* Corresponding author: dsxncslglz@163.com
} 
where $x_{i}^{[\mathrm{B}]}$ and $x_{i}^{[\mathrm{A}]}$ designate the central vectors of particles (or balls) A and B. Hence, the dynamical distnance between A and B can be defined by Eq. (2),

$$
\begin{aligned}
d & =\left|x_{i}^{[\mathrm{B}]}-x_{i}^{[\mathrm{A}]}\right| \\
& =\sqrt{\left(x_{i}^{[\mathrm{B}]}-x_{i}^{[\mathrm{A}]}\right)\left(x_{i}^{[\mathrm{B}]}-x_{i}^{[\mathrm{A}]}\right)}
\end{aligned}
$$

XFEM was also applied in this study to predict the successive slide in the marine embankment. The subdomain integration has been invited in XFEM to realize the field summation on the discrete interpolative functions, by which the discrete functions' integreation were solved victorily. The goal numerical function can be expressed as Eqs. (3) and (4),

$$
\left(\begin{array}{ll}
M_{u u} & M_{u q} \\
M_{q q} & M_{q q}
\end{array}\right)\left(\begin{array}{l}
\ddot{u} \\
\ddot{q}
\end{array}\right)+\left(\begin{array}{ll}
K_{u u} & K_{u q} \\
K_{q q} & K_{q q}
\end{array}\right)\left(\begin{array}{l}
u \\
q
\end{array}\right)=\left(\begin{array}{l}
f^{e x t} \\
Q^{e x t}
\end{array}\right)
$$

$$
K=K^{m a t}+K^{g e o}
$$

where, $u$ designates the nodal freedom, $q$ refers to the additional nodal freedom due to the internal breach of the goal element, $M$ and $M_{u q \text { represent the coupled items of }}$ the mass matrices on $u$ and $q, K, K_{u q}, K^{\text {mat }}$ and $K^{\text {geo }}$ define the global rigid matrix, the coupled item, the physical and geometrical rigidities, $f^{\text {ext }}$ is the external force on $u, Q^{e x t}$ is the external force on $q$.

\section{Constitution of the marine embankment}

The properties of the marine embankment were summarized into 5 categories, namely, debris, sliding zones, geo-matrix, revetment and riprap. The typical values of the 5 categories were shown in Tab. $1^{[4,5]}$,

Tab.1 Typical values of marine embankment properties

\begin{tabular}{ccccccc}
\hline Categories & $\begin{array}{c}\text { Unit gravity } \\
/ \mathbf{k N} / \mathbf{m}^{\mathbf{3}}\end{array}$ & $\begin{array}{c}\text { Modulus } \\
/ \mathbf{M P a}\end{array}$ & $\begin{array}{c}\text { Poisson } \\
\text { ratio }\end{array}$ & $\begin{array}{c}\text { Cohesion } \\
/ \mathbf{k P a}\end{array}$ & $\begin{array}{c}\text { Internal } \\
\text { friction } \\
/ 0\end{array}$ & $\begin{array}{c}\text { Dilative } \\
\text { angle/0 }\end{array}$ \\
\hline Debris & 17.00 & 0.06 & 0.35 & 6 & 15 & 0 \\
Sliding zones & 17.90 & 0.20 & 0.30 & 10 & 17 & 0 \\
Geo-matrix & 20.00 & 0.90 & 0.29 & 26 & 23 & 0 \\
Revetment & 19.00 & 1.50 & 0.23 & 200 & 36 & 0 \\
Riprap & 26.00 & 1.00 & 0.27 & 10 & 28 & 0 \\
\hline
\end{tabular}

Mohr-Coulomb model was adopted to express the yielding characteristics of the geo-blocks in Eq. (5),

$$
f=\left(\sigma_{1}-\sigma_{3}\right)_{f}-\frac{2 c \cos \phi+2 \sigma_{3} \sin \phi}{1-\sin \phi}
$$

where, $c$ and $\phi$ represent the shear strength indexes, $\sigma_{1}$ and $\sigma_{3}$ refer to the principal stresses.

\section{Designs on boundary conditions}

The initial sliding zones in the debris were depicted by 3point arcs that ran commonly into the embankment for $3 \mathrm{~m}$ ${ }^{[6]}$. The debris bodies include two varities, i.e., sharp wallball and polygonal wall-ball zones that were shown in Fig. 3.

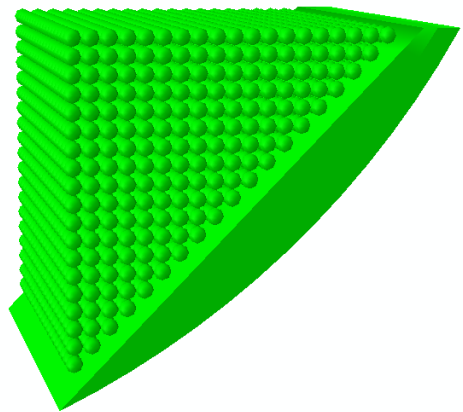

(a) Sharp wall-ball debris

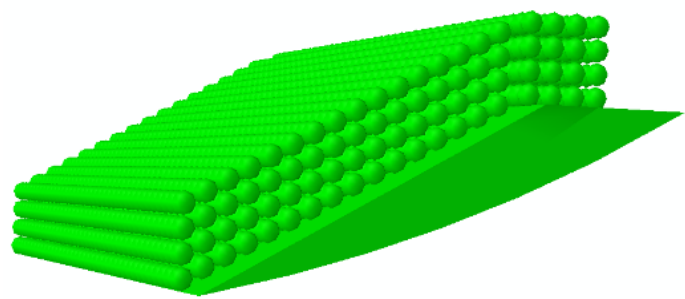

(b) Polygonal wall-ball debris

Fig.3 Designed boundary conditions 


\section{Results}

The numerical results were derives with DEM and XFEM technologies as follows.

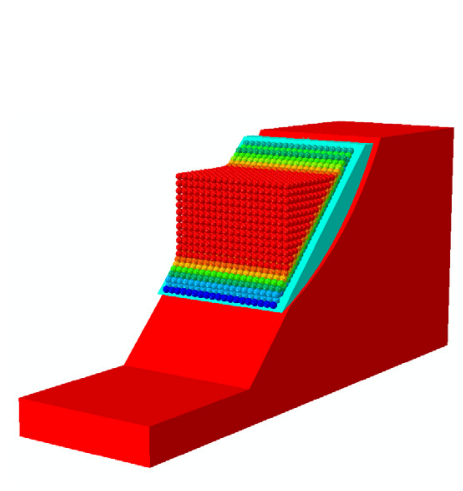

(a)Step1

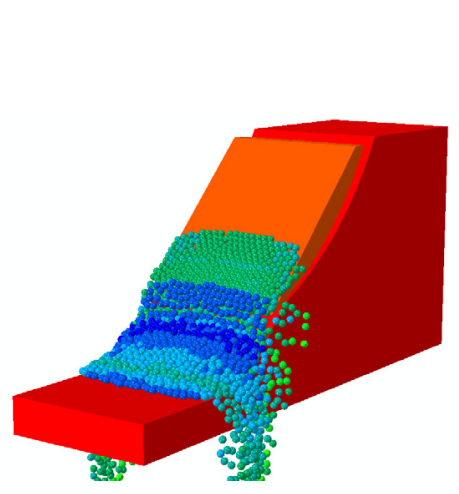

(b) Step2

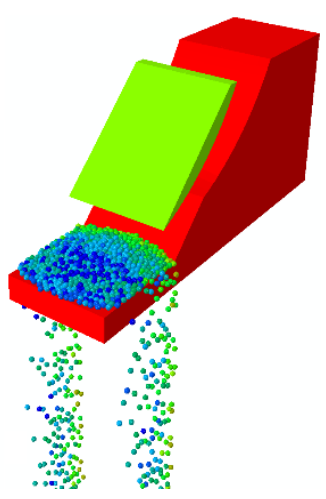

(c) Step3

Fig.4 Dynamical displacement field

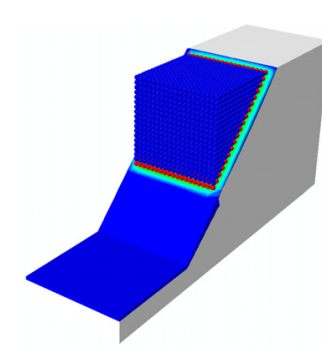

(a)Step1

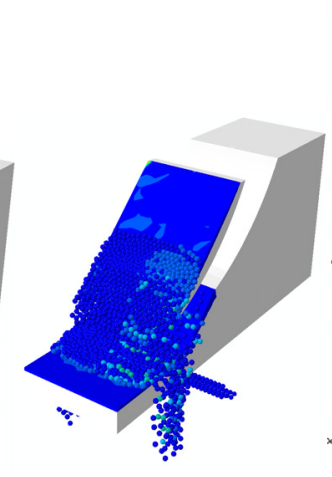

(b) Step2

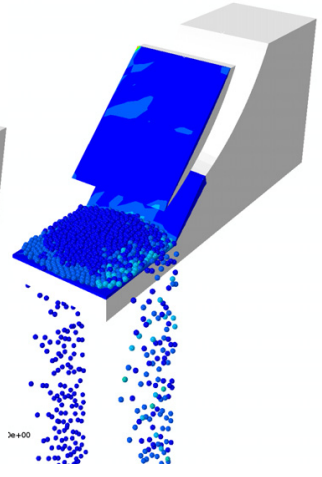

(c) Step3

Fig.5 Dynamical internal friction field

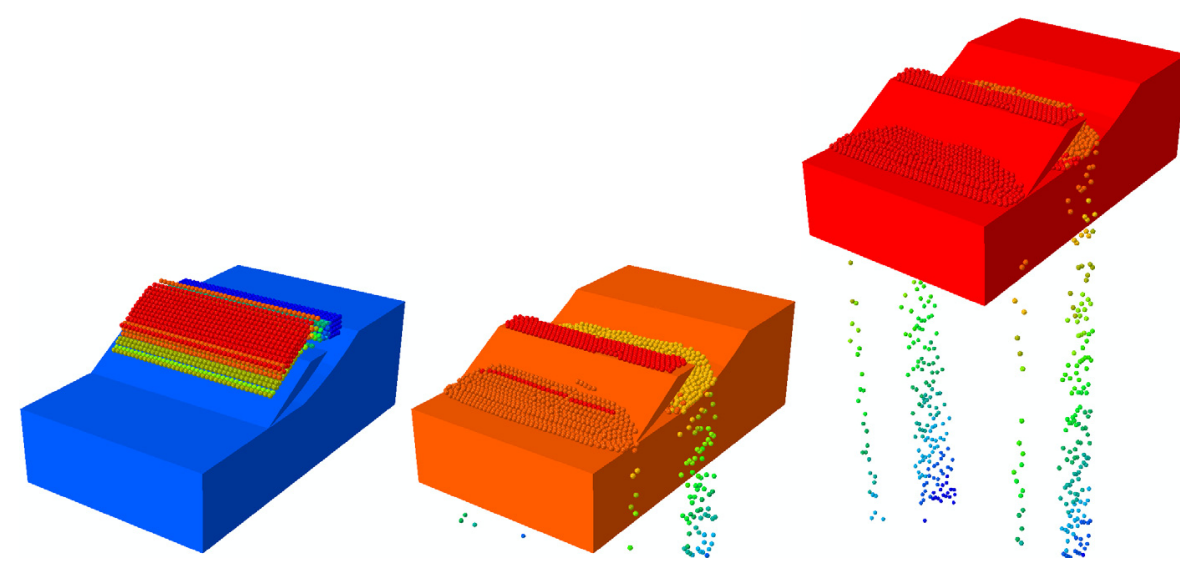

(a)Step1

(b) Step2

(c) Step3

Fig.6 Dynamical displacement field 


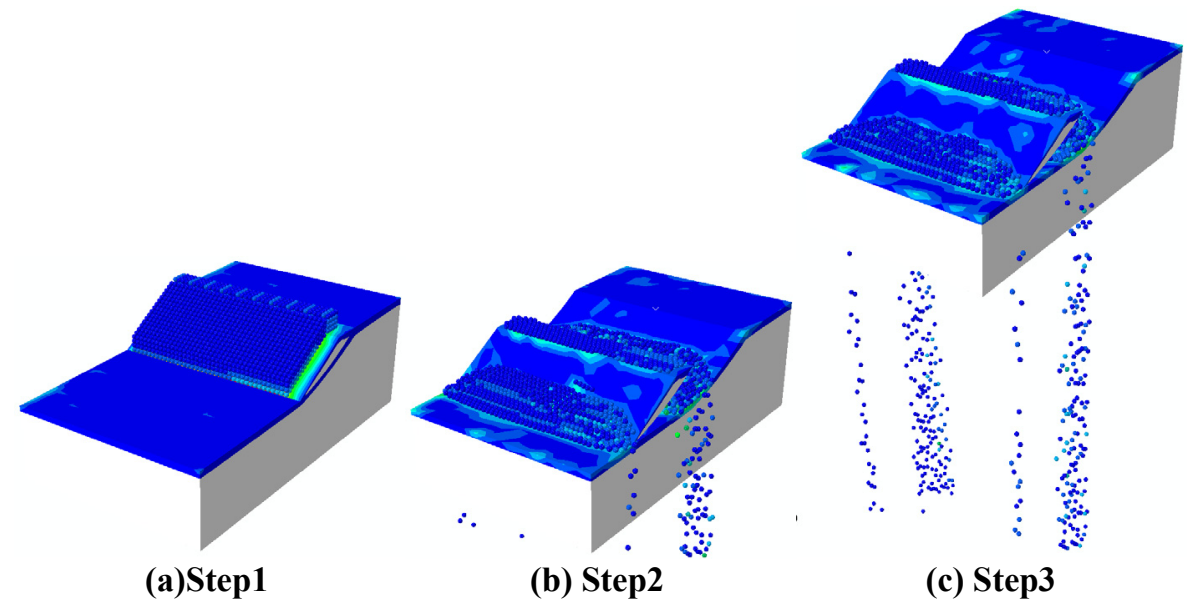

Fig.7 Dynamical internal friction field

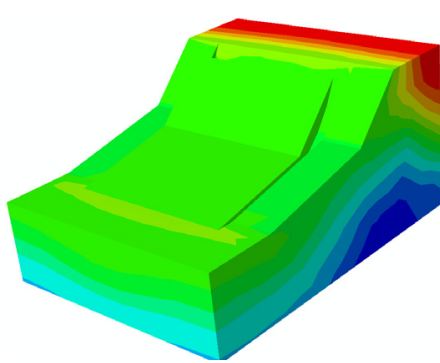

(a)Step1

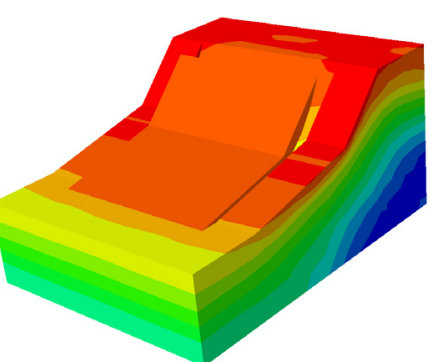

(b) Step2

Fig.8 Principal stress field of single slide

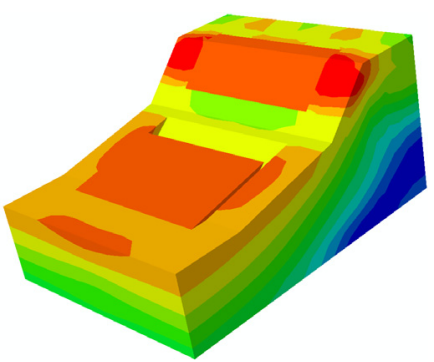

(a)Step1

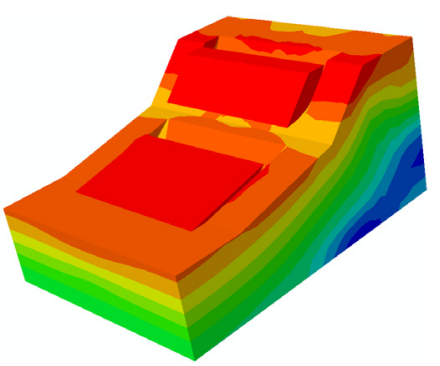

(b) Step2

Fig.9 Principal stress field of double slides

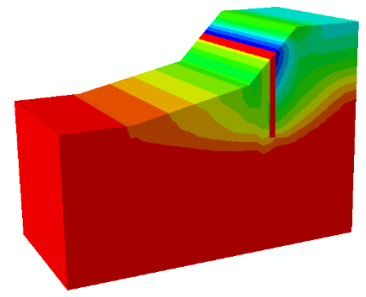

(a)Global field

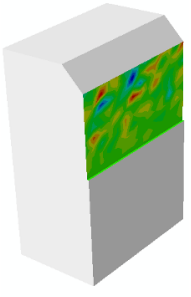

(b) Local distrbution

Fig.10 Revetment displacement field

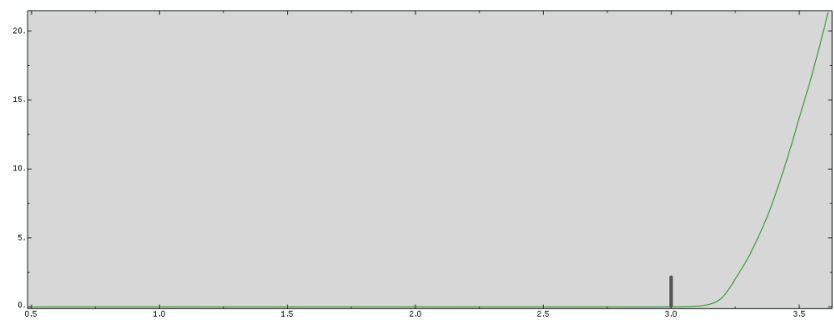

Fig.11 Reliability factor 


\section{Discussions and conclusions}

The stuff block more than $200 \mathrm{~m}^{3}$ ran down into ocean during less than $12 \mathrm{~s}$ under the Sharp wall-ball B.C. The internal hydro-dynamic traction was the main cause and the collapsed debirs showed the radial mat distribution.

The kinematic sliding zone with $5 \mathrm{~m}$ depth was swept into ocean under the internal seeping pressure which kept at the level of $10 \mathrm{kPa}$. The destroyed volume of the stuff block was more than $600 \mathrm{~m}^{3}$. The maximal value of stuff sliding loss was $630 \mathrm{~m}^{3} / 35 \mathrm{~s}$ under under the internal seeping pressure.

The designed revetment system reinforced the marine embankment the internal friction density of which kept at the level of $2 \mathrm{MPa}$. Moreover, the level of interfacial open was less than $1 \mathrm{~mm}$.

The reinforced depth in the embankment was more than $16 \mathrm{~m}$ and the global reliability factor attained 2.6 which indicated that the designed revetment system was the admirable one.

Acknowledgements: This research was funded by National Natural Science Foundations of China, grant numbers 51879236 and 51109118 and Zhejiang Provincial Natural Science

Foundation of China, grant number LHY21E090003.

\section{References}

1. Sha, G. (1984) On the virtual crack extension technique for stress intensity factors and energy release rate calculation for mixed fracture modes. International Journal of Fracture, 25(2) 33-42.

2. Remmers, J.J.C., Wells, G.N. and de Borst, R. (2003) A solid-like shell element allowing for arbitrary delaminations. International Journal for Numerical Methods in Engineering, 58, 2013-2040.

3. Chowdhury, S.R. and Narasimhan, R. (2000) A cohesive finite element formulation for modelling fracture and delamination in solids. Saadhana, 25 (6), 561-587.

4. Yajun WANG, Jin feng, Zhang chuhan, Wang jun. Primary physical-mechanical characteristics on marine sediments from Zhoushan Seas in Sino mainland[J]. Applied Mechanics and Materials, 2013, Vol 275-277: 273-277

5. Yajun WANG, Hu Yu, Zuo Zheng, Gan Xiao Qing, Dong Zhi Hong. Stochastic Mechanical Characteristics of Zhoushan Marine Soil Based on GDS Test System[J]. Advanced Materials Research, 2013, Vol 663: 676 679

6. Yajun WANG. A novel story on rock slope reliability, by an initiative model that incorporated the harmony of damage, probability and fuzziness[J]. Geomechanics and Engineering, 2017, 12(2): 269294. 